Brazilian Journal

of Chemical

ISSN 0104-6632

Engineering

\title{
VALIDATION OF THE SULFO-PHOSPHO- VANILLIN (SPV) METHOD FOR THE DETERMINATION OF LIPID CONTENT IN OLEAGINOUS MICROORGANISMS
}

\author{
A. Anschau ${ }^{1 *}$, C. S. Caruso 2 , R. C. Kuhn ${ }^{3}$ and T. T. Franco ${ }^{4}$ \\ ${ }^{1}$ Department of Bioprocess Engineering and Biotechnology, Federal University \\ of Technology, (UTFPR), CEP: 85660-000, Dois Vizinhos - PR, Brazil. \\ Phone: +554635368438 \\ E-mail: andreiaanschau@utfpr.edu.br \\ ${ }^{2}$ Development and Technological Innovation Agency, University of Estácio de Sá, \\ CEP: 1405-0410, Rio de Janeiro - RJ, Brazil. \\ ${ }^{3}$ Department of Chemical Engineering, Federal University of Santa Maria, (UFSM), \\ CEP: 97105-900, Santa Maria - RS, Brazil. \\ ${ }^{4}$ Department of Chemical Processes, School of Chemical Engineering, State \\ University of Campinas, (UNICAMP), CEP: 13083-862, Campinas - SP, Brazil.
}

(Submitted: December 10, 2014 ; Revised: July 18, 2015 ; Accepted: September 15, 2015)

\begin{abstract}
A colorimetric sulfo-phospho-vanillin (SPV) method was used to validate a high throughput method for total lipids analysis in fresh and lyophilized oleaginous microorganisms. This method uses a small amount of biological material, does not require a lot of sample manipulation, can be automated, is reproducible and easy to implement. A 96-well microplate SPV assay allows one to determine quickly total lipids in lyophilized cells of oleaginous yeast and microalgae. The new assay method possesses many advantages compared to the others described in the literature: requires a small amount sample, less time (around $1 \mathrm{~h}$ ) and less labor and does not require organic reagents like chloroform in the reaction.

Keywords: Colorimetric method; Microplate; Oleaginous yeast and microalgae; Lipid.
\end{abstract}

\section{INTRODUCTION}

The screening of oleaginous organisms has extensive application in both research and industry settings for identifying and producing food supplements and renewal biofuels (Ratledge 2002). With improved technological and analytical capabilities, "microquantity" approaches that require only micrograms of sample and microlitres of solvents have been developed for estimating lipid content. Stand ard lipid analyses require large amounts of sample and the development of micro-methods would reduce this need.

The SPV reaction is performed in two steps, initial reaction of the lipids with concentrated sulfuric acid at high temperature followed by a second reaction of the derived products with vanillin in the presence of phosphoric acid. Consensus understanding is that a positive SPV reaction requires the presence of double bonds or free hydroxyl groups within the

*To whom correspondence should be addressed 
lipid analytes (Johnson et al., 1977; Knight et al., 1972). The chemical reactions are complex and are thought to involve the formation of relatively stable (up to several hours) (Johnson et al., 1977) carbonium ion (or carbocation) chromogens (alkenyl cations) in the initial reaction followed by generation of a pink chromophore upon addition of vanillin to the reaction (Cheng et al., 2011; Frings et al., 1972; Inouye et al., 2006; Johnson et al., 1977; Knight et al., 1972).

The choice of the standard is important, since saturated fatty acids do not form a chromogen and are not detected. In addition, the reactivity of polyunsaturated fatty acids decreases with increasing unsaturation (Knight et al., 1972). The SPV method has been modified for diverse applications such as the determination of total lipids in serum, food and ecological samples (Desvilettes et al., 1997; Haskins et al., 2010; Knight et al., 1972; Nakamatsu et al., 2004; Turlo et al., 2010; Visavadiya et al., 2009).

To date, studies were carried out using different ratio combinations of organic solvents, such as chloroform and methanol as a preliminary step (Cheng et al., 2011; Inouye et al., 2006). In our study, the first step of organic solvent addition was eliminated. Consequently, the method became more cost-effective and reaction time decreased significantly. Transfer of reactants to proper containers was required for absorbance measurement. Since color develops continuously, careful sample handing and control of color development are critical when using this micro-scale approach. The use of 96-well microplates to read the colored product allowed faster measurement of multiple samples with easy background correction, more consistent monitoring of color development and a cost reduction. As an example, total lipids in extracts from microalgae, which contain a dark green background, were successfully measured using this assay approach with olive oil as a standard.

A validation of an analytical method is fundamental to implementing a quality control system in any analytical laboratory (Ribani et al., 2004). The analytical parameters typically found for quantitative method validation are: selectivity, linearity, precision, accuracy, limit of detection, limit of quantification and robustness. The SPV method has been recommended as an acceptable procedure for routine use, but its accuracy depends primarily on the reference standard used (Knight et al., 1972). We verified the impact of the described modification on the validation parameters using oleic (unsaturated) and palmitic (saturated) acids as reference standard.

\section{MATERIAL AND METHODS}

\section{Cultivation Conditions of Oleaginous Yeast and Microalgae}

Oleaginous yeast Lipomyces starkeyi DSM 70296 was cultivated in fed-batch system. The medium and fermentation conditions were the same as described by Anschau et al. (2014).

Oleaginous microalgae Chlorella vulgaris CPCC90 was cultivated in a fed-batch system. Stock cultures were propagated and maintained on synthetic BBM medium, at the following composition (per liter): $\mathrm{NaNO}_{3}, 0.25 \mathrm{~g} ; \mathrm{KH}_{2} \mathrm{PO}_{4}, 0.175 \mathrm{~g} ; \mathrm{H}_{3} \mathrm{BO}_{3}, 0.115 \mathrm{~g}$; $\mathrm{K}_{2} \mathrm{HPO}_{4}, 0.075 \mathrm{~g} ; \mathrm{MgSO}_{4} .7 \mathrm{H}_{2} \mathrm{O}, 0.075 \mathrm{~g} ; \mathrm{KOH}, 0.031$ g; $\mathrm{CaCl}_{2} .2 \mathrm{H}_{2} \mathrm{O}, 0.025 \mathrm{~g} ; \mathrm{NaCl}, 0.025 \mathrm{~g} ; \mathrm{Na}_{2}$ EDTA, $0.01 \mathrm{~g} ; \mathrm{FeSO}_{4} .7 \mathrm{H}_{2} \mathrm{O}, 0.0049 \mathrm{~g} ; \mathrm{MnCl}_{2} .4 \mathrm{H}_{2} \mathrm{O}, 1.81 \mathrm{mg}$; $\mathrm{NaMoO}_{4} .5 \mathrm{H}_{2} \mathrm{O}, 0.390 \mathrm{mg} ; \mathrm{ZnSO}_{4} .7 \mathrm{H}_{2} \mathrm{O}, 0.222 \mathrm{mg}$; $\mathrm{CuSO}_{4} .5 \mathrm{H}_{2} \mathrm{O}, 0.079 \mathrm{mg} ; \mathrm{CoCl}_{2} .6 \mathrm{H}_{2} \mathrm{O} 0.0404 \mathrm{mg}, \mathrm{pH}$ 6.8. The incubation conditions used were $26^{\circ} \mathrm{C}$, photon flux density of $15 \mu \mathrm{molm} \mathrm{m}^{-2} \mathrm{~s}^{-1}$ and a photoperiod of $12 \mathrm{~h}$.

Cultures of both yeast and microalgae were harvested at the end of the cultivation, centrifuged at 2,000 $\mathrm{g}$ for $10 \mathrm{~min}$ and the retained pellet was lyophilized. Fresh and lyophilized cells were used for colorimetric assay using microplates and the results were compared with the total lipid measured using the macro-gravimetric method (Bligh et al., 1959).

\section{Sulfo-Phospho-Vanillin (SPV) Method}

\section{Reagents}

ACS grade concentrated sulfuric acid and $o$ orthophosphoric acid (85\%) were purchased from Ecibra (Brazil). Vanillin (98\%), palmitic acid and oleic acid were purchased from Sigma-Aldrich (USA). Commercial olive oil was obtained from a local market. Phosphovanilin (PV) reagent was prepared by using six milligrams of vanillin dissolved in $100 \mathrm{~mL}$ of hot water and further diluted to $500 \mathrm{~mL}$ with $85 \%$ phosphoric acid. Oleic acid was used as standard and diluted properly with concentrated sulfuric acid to reach $1 \mathrm{mg} \cdot \mathrm{mL}^{-1}$.

\section{Sample Preparation}

Stock solutions of fresh and lyophilized cells of yeast $\left(2.5 \mathrm{mg} \cdot \mathrm{mL}^{-1}\right)$ and of microalgae $\left(0.41 \mathrm{mg} \cdot \mathrm{mL}^{-1}\right)$ were used. Lyophilized cells were dissolved separately in sulfuric acid. Standard samples were prepared by mixing oleic acid in sulfuric acid. Fresh 
cells were ressuspended in distilled water and diluted as necessary. The absorbance of the solution was measured at $600 \mathrm{~nm}$ and its value converted to dry biomass using the corresponding calibration curve. After centrifugation at 2,000 $\mathrm{g}$ for $10 \mathrm{~min}$, the retained pellet was dissolved in sulfuric acid to achieve the desirable concentration.

\section{SPV Reaction}

Twenty microliters of samples (with and without oleic acid) were diluted in $180 \mu \mathrm{L}$ of concentrated sulfuric acid in test tubes and incubated at $100{ }^{\circ} \mathrm{C}$ for $10 \mathrm{~min}$. Then, the tubes were cooled to room temperature and $0.5 \mathrm{~mL}$ of $\mathrm{PV}$ reagent was added for color development (Figure 1). The mixture was incubated at $37^{\circ} \mathrm{C}$ for $15 \mathrm{~min}$. Samples were transferred to polystyrene 96-well microplates and stored for 45 min in a dark box. Then, the absorbance was measured at $530 \mathrm{~nm}$ by a multilabel plate reader (Perkin Elmer, USA) and results expressed as absorbance.

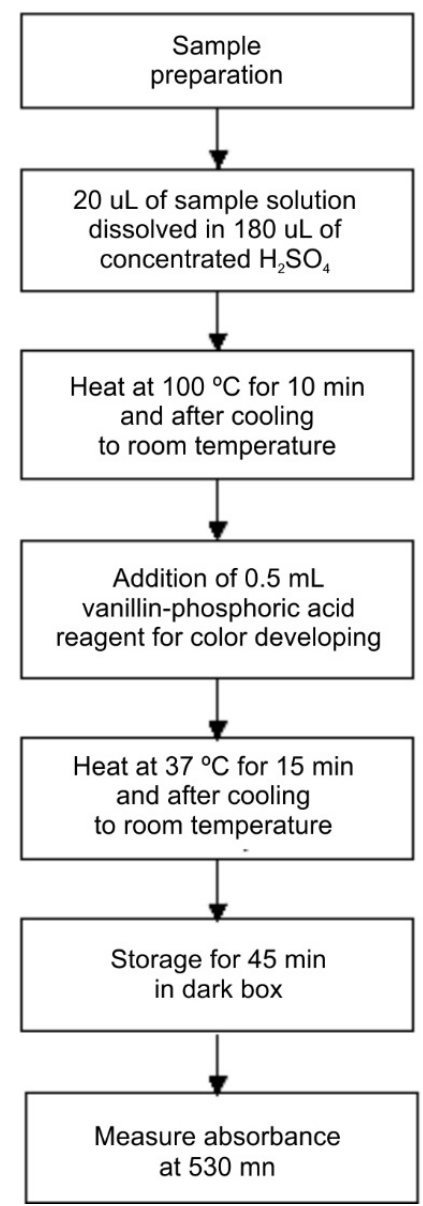

Figure 1: General scheme procedure adopted for SPV method validation.

\section{Preliminary Studies}

Solvents, including different ratios of chloroform and methanol (hexane, chloroform, methanol, chloroform:methanol (1:1), chloroform:methanol (1:2) and ethanol), were tested to determine the effect of sample preparation on the assay. Samples containing olive oil in solvent mixtures (15 $\mathrm{mg}$ olive oil per $\mathrm{mL}$ solvent) were pipetted into the microplate wells by varying the volume from 1 to $20 \mu \mathrm{L}$. The solvent was evaporated at $90{ }^{\circ} \mathrm{C}$, and then $180 \mu \mathrm{L}$ of concentrated sulfuric acid was added. The microplate was then incubated on a dry heating bath at $100{ }^{\circ} \mathrm{C}$ for 10 min. Then, the tubes were cooled to room temperature and $0.5 \mathrm{~mL}$ of $\mathrm{PV}$ reagent was added for color development (Figure 1). The mixture was incubated at $37^{\circ} \mathrm{C}$ for $15 \mathrm{~min}$. Samples were transferred to polystyrene 96-well microplates and stored for 45 min in a dark box. Then, the absorbance was measured at $530 \mathrm{~nm}$ by a multilabel plate reader (Perkin Elmer, USA) and results expressed as absorbance. All the analyses were performed in triplicate and error bars denote the standard deviation.

According to Chen et al. (2009) the color development is a time function. To assess this parameter, the color produced in the SPV reaction with different concentrations of oleic acid ( 0 to $\left.0.20 \mathrm{mg} \cdot \mathrm{mL}^{-1}\right)$ was monitored during $60 \mathrm{~min}$ at $530 \mathrm{~nm}$. During this time, plates with samples were kept in the multilabel plate reader (in the dark) and absorbance values collected each 15 min (Figure 1). After calculating each sample absorbance, the Tukey HSD test was applied to assess differences in the mean absorbance obtained versus the storage time in the dark.

\section{Validation Parameters}

The method was validated according to the Brazilian National Agency of Sanitary Vigilance (Anvisa, 2003) and the International Conference on Harmonisation Guidelines for validation of analytical procedures from the regulatory bodies of the European Union, Japan and USA (Harmonisation, 1996).

\section{Preliminary Tests}

The absorbance profile of the colored product was checked between 400 and $600 \mathrm{~nm}$, prior to the specificity and selectivity tests. Selecting an appropriate standard is important for assessing lipid content in different types of samples. Palmitic and oleic acid (1:1) were used as standards for the colorimetric method because yeast and microalgae lipids usually have this ratio and are relatively close in composition to palm oil (Anschau et al., 2014). 


\section{Specificity and Selectivity}

To verify whether any compound in the sample (fresh and lyophilized) matrix interfered in the assay, two analytical curves were constructed: one curve with only oleic acid at $0,0.025,0.05,0.10,0.15,0.20$ mg.mL ${ }^{-1}$ (equivalent to $5,10,20,30$ and $40 \mu \mathrm{g}$ of lipids) and another curve contaminated with $15 \mu$ of sample (equivalent to $42.5,47.5,57.5,67.5,77.5 \mu \mathrm{g}$ lipids). After sample preparation, the direct reaction was performed as previously described.

\section{Linearity, Limit of Detection (LD) and Limit of Quantification (LQ)}

The linearity was evaluated by linear regression analysis, which was calculated by the least square regression method. The calibration curves were constructed by plotting concentration versus absorbance, using linear regression analysis. The linearity was determined by adding separately oleic acid at 0 , $0.025,0.05,0.1,0.15$ and $0.2 \mathrm{mg} \cdot \mathrm{mL}^{-1}$ to $15 \mu \mathrm{L}$ of sample by the standard addition method (Ribani et al., 2004). This method can be applied to selectivity studies when it is not possible to obtain a free matrix from the substance of interest. Linearity was determined by plotting absorbance versus lipid amount in the assay and examining the $R^{2}$ value upon linear regression of the data. The LD and LQ were calculated as $3.3 \mathrm{\sigma} / \mathrm{S}$ and $10 \mathrm{\sigma} / \mathrm{S}$, respectively (Harmonisation, 1996), where $S$ is the slope of the calibration curve and $\sigma$ is the standard deviation of the intercept of the regression equation.

\section{Precision and Accuracy}

In a validation study, repeatability and recovery are considered as precision and accuracy parameters, respectively. Precision was expressed as the relative standard deviation (RSD \%) and accuracy was expressed as the mean relative error (RME \%). The instrumental precision was found by measuring the absorbance at $530 \mathrm{~nm}$ for 18 replicates (Harmonisation, 1996). The precision and accuracy studies were performed with different amounts of lyophilized cells and sulfuric acid in comparison to the procedure shown in Figure 1, but with the same final reaction volume of $40 \mu \mathrm{L}$ by adding oleic acid solution. In this case the standard addition method was used to minimize errors and to make sure that the measurements fell on a linear plot. The reaction was prepared in a polypropylene tube $(1.5 \mathrm{~mL})$ adding $40 \mu \mathrm{L}$ of lyophilized cell solution $\left(2.5 \mathrm{mg} \cdot \mathrm{mL}^{-1}\right), 40 \mu \mathrm{L}$ oleic acid solution $\left(1 \mathrm{mg} \cdot \mathrm{mL}^{-1}\right)$ and $120 \mu \mathrm{L}$ of sulfuric acid.
The repeatability was determined from the standard deviation of the samples in triplicate spiked with different concentrations of oleic acid ( 0 to 0.20 $\left.\mathrm{mg} \cdot \mathrm{mL}^{-1}\right)$. The accuracy of the method was determined by a recovery test using the same samples prepared for the linearity test and the percentage calculated according Equation (1):

$R(\%)=\left(\frac{C a(s a+s t)-C a(s a)}{C b}\right) \times 100$

where $C a$ is the experimental concentration $\left(\mathrm{mg} \cdot \mathrm{mL}^{-1}\right)$, $s a$ is the sample, st is the standard, $C a(s a)$ is the experimental sample concentration (blank), (mg. $\mathrm{mL}^{-1}$ ), and $C b$ is the theoretical concentration $\left(\mathrm{mg} \cdot \mathrm{mL}^{-1}\right)$.

\section{Robustness}

The SPV method should be divided in two parts: first, the sample reacts with sulfuric acid at $100^{\circ} \mathrm{C}$ and then it is incubated at $37{ }^{\circ} \mathrm{C}$ with PV reagent. Since it is known that sulfuric acid must be concentrated and the humidity interferes in the results (Cheng et al., 2011; Knight et al., 1972), the robustness was verified by a $2^{3}$ full factorial design (FFD) with three replicates at the center point (leading to eleven experiments), varying some of the parameters from the second part of the reaction: reaction temperature, reaction time and volume of PV reagent (Table 1).

A Pareto chart was made for the analysis of each response coefficient for its statistical significance. Quantitative and qualitative contribution of each variable to each of the responses was analyzed. Possible interactions between $\mathrm{X}_{1} \mathrm{X}_{2}, \mathrm{X}_{2} \mathrm{X}_{3}$, and $\mathrm{X}_{1} \mathrm{X}_{3}$ were also studied. The statistical analyses were performed using STATISTICA 7.0 (Statsoft Inc. 2325, Tusla, OK).

Table 1: Factorial design $2^{3}$ with values of real and coded levels.

\begin{tabular}{|l|c|c|c|}
\hline Variable & $\mathbf{- 1}$ & $\mathbf{0}$ & $\boldsymbol{+ 1}$ \\
\hline PV Volume, $\mathrm{mL}\left(x_{1}\right)$ & 0.3 & 0.5 & 0.7 \\
Time, min $\left(x_{2}\right)$ & 13 & 15 & 17 \\
Temperature, ${ }^{\circ} \mathrm{C}\left(x_{3}\right)$ & 34 & 37 & 40 \\
\hline
\end{tabular}

\section{RESULTS AND DISCUSSION}

\section{Preliminary Tests}

In tests of lipid measurement using hexane and ethanol as organic solvents, the color development 
was higher in comparison with the other solvents or with no solvent addition. The final standard curve presented similar linearity with an $\mathrm{R}^{2}$ higher than 0.99 in all studies. In this work, the first step of organic solvent addition was eliminated.

Knight et al. (1972) proposed a reaction sequence where the carbonium ion reacts with one activated carbonyl group of PV to former the colored complex product. Since this product should be stabilized after reaction, they used $45 \mathrm{~min}$ as storage time. In this study, Tukey analysis $(\mathrm{p}<0.05)$ showed that the colored product was stable after 30 minutes. To ensure that the time will not interfere in the results, it was decided to measure the absorbances after $45 \mathrm{~min}$ of storage in the dark.

No significant difference (according to the Tukey HSD test) was found in lipid determinations when lipid content was measured using the new method (44 $\pm 0.8, \%)$ and compared to results obtained using a macro-gravimetric method $(42.7 \pm 1.5, \%)$.

There is a concern that using conventional Folch extraction and gravimetric lipid quantification may result in lipophilic proteins and pigments being included in the calculated lipid weight. This may be the reason why many of the reported studies overestimate the absolute microalgae lipid content (Bellou et al., 2012; Makri et al., 2011). All of these problems can be avoided in the SPV process due to the fact that all of these extra products are degraded by acid-thermal treatment."

Landrum et al. (2002) demonstrated that the micro-colorimetric SPV and micro-gravimetric methods produce comparable results for aquatic algae. For $\mathrm{Lu}$ et al. (2008), the lack of difference between two micro-quantity approaches for organisms of both low (algae) and high (somatic and gonadal fish tissue) total lipid content indicated that comparison of studies using these two methods can be conducted with little concern for potential bias.

The major function of the sulfuric acid is to hydrolyze the lipid esters. Knight et al. (1972) stated that the initial reaction takes place in concentrated sulfuric acid in which the serum-to-acid ratio was 1:50. If hydrolysis were the only process, less concentrated acid should give equivalent results. Our study used a cell solution-to-acid ratio of 1:9. Knight et al. (1972) also studied the effect of the presence of water in the reaction. Concentrated sulfuric acid is the only one in which an appreciable reaction takes place. Using a water-to-acid ratio of 1:3, the color development was minimal. Water-to-acid ratios of 1:1 and 3:1 did not result in color development at $525 \mathrm{mn}$.

Considering SPV as a useful analytical tool to quantify lipid content in fresh and lyophilized cells (yeast and microalgae) after the fermentation process, it is important to validate this method by evaluating analytical parameters such as specificity, selectivity, linearity, LD, LQ, precision, accuracy and robustness.

\section{Specificity and Selectivity}

Prior to the selectivity test, an absorbance profile (400 to $600 \mathrm{~nm}$ ) was checked for reactions with cell solutions and with oleic acid. The profiles obtained were similar, except the sample contaminated with oleic acid rendered higher absorbance values in the $\lambda \max$ region (data not shown). This procedure ensured that palmitic acid, a saturated oil, does not interfere in the analysis. Considering that the SPV reaction is specific to unsaturated lipid (Knight et al., 1972), to confirm the specificity of the method calibration curves were compared with oleic acid and with a mixture of palmitic acid and oleic acid (1:1 $\left.\mathrm{w} . \mathrm{w}^{-1}\right)$. In Figure 2, is observed that, in fact, palmitic acid at this concentration does not interfere in the analysis because absorbance values of the mixture match with half of the absorbance values of pure oleic acid. However, tests performed in triplicate with higher concentration of pure palmitic acid $(2.5$ g. $\left.L^{-1}\right)$ showed high absorbance $(0.641 \pm 0.031)$, resulting in a nonlinear response and counteracting the reaction mechanism proposed by other authors (Knight et al., 1972).

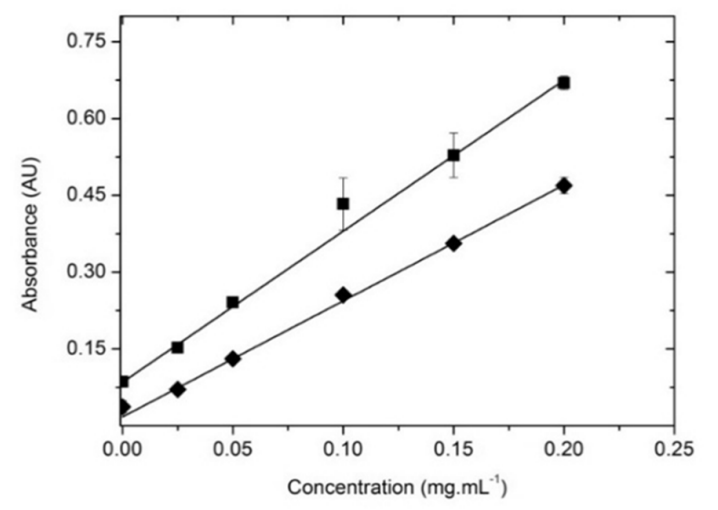

Figure 2: Calibration curves of the product formed by the SPV reaction with pure oleic acid (- $)$ and in a mixture of palmitic acid:oleic acid $\left(1: 1 \mathrm{w}^{-1} \mathrm{w}^{-1}\right)(\bullet)$.

The selectivity test was performed using the standard addition method (Ribani et al., 2004). The method is considered to be selective if calibration curves are parallel. If calibration curves cross, the method is not considered to be selective and suffers matrix interference. The calibration curves of oleic 
acid with and without yeast cell spiking are presented in Figure 3.

It is observed that only lyophilized cells did not interfere in the colorimetric reaction and the response (absorbance) was linear between 0 and 0.2 $\mathrm{mg} \cdot \mathrm{mL}^{-1}$ of oleic acid. In this interval, other validation parameters were calculated, e.g., precision and accuracy. The calibration curves of oleic acid with and without lyophilized microalgae cell spiking are presented in Figure 4.
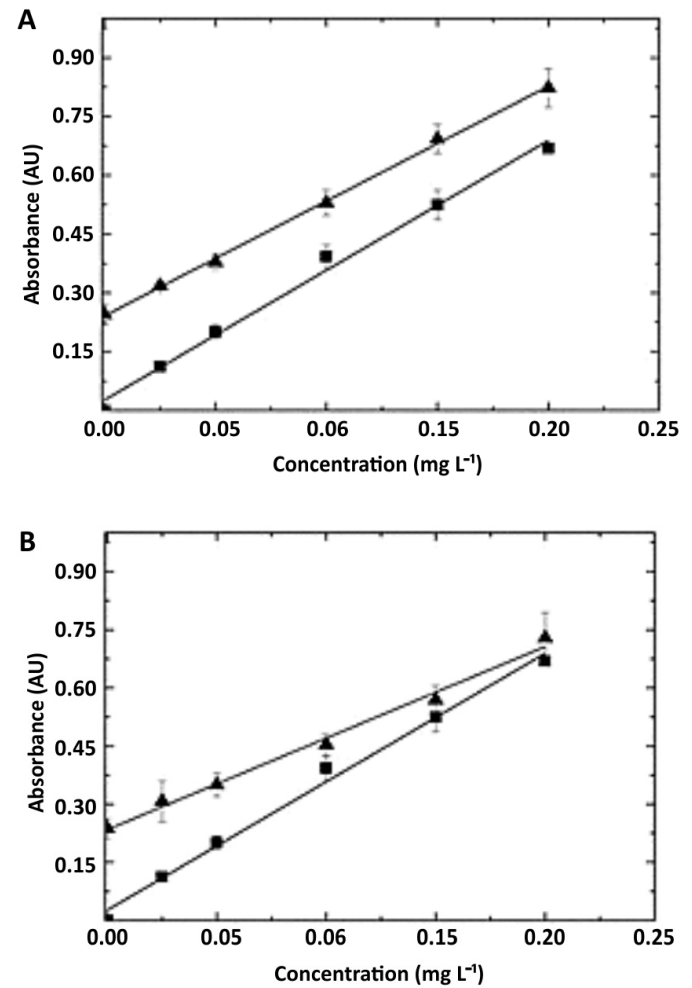

Figure 3: Calibration curves of the product formed by the SPV reaction with (A) lyophilized yeast cells and (B) fresh yeast cells, with addition of oleic acid $(\mathbf{- )}$ ) and the mixture of oleic and palmitic acid ( $\mathbf{\Lambda})$. The first graph compares the oleic acid calibration curve $\left(\mathrm{r}^{2}=0.9926\right)$ with a mixture containing lyophilized cells $\left(r^{2}=0.9995\right)$. The second graph compares pure oleic acid $\left(\mathrm{r}^{2}=0.9926\right)$ curve with a mixture containing fresh cells $\left(\mathrm{r}^{2}=0.9875\right)$.

\section{Linearity, Detection and Quantification Limits}

Under the specified optimum reaction conditions, the calibration curves were constructed with the reagents employed in the present work. The regression equations for the results were derived using the leastsquares method. In all cases, Beer's law plots $(n=3)$ were linear with very small intercepts and good correlation coefficients in the general concentration range up to $0.20 \mathrm{mg} \cdot \mathrm{mL}^{-1}$ of biomass (equivalent to 42.5 to $77.5 \mu \mathrm{g}$ of lipids). The LD was found to be $28 \mu \mathrm{g} \cdot \mathrm{mL}^{-1}$ of lipids for lyophilized cells and 35 $\mu \mathrm{g} . \mathrm{mL}^{-1}$ of lipids for fresh cells. The LQ achieved was $84 \mu \mathrm{g} \cdot \mathrm{mL}^{-1}$ for lyophilized cells and $106 \mu \mathrm{g} \cdot \mathrm{mL}^{-1}$ for fresh cells.

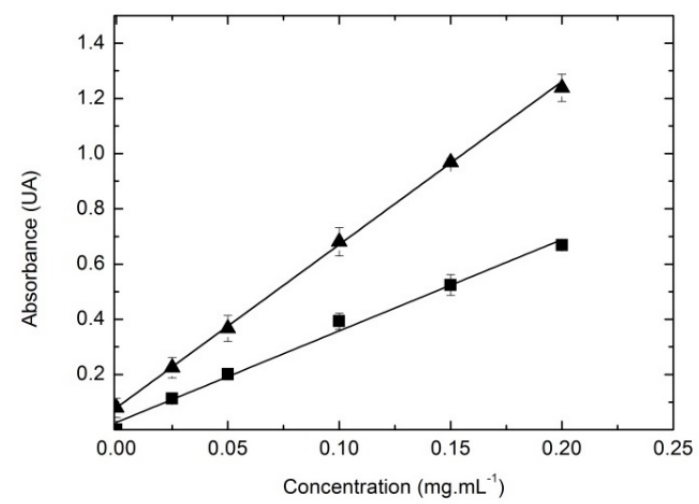

Figure 4: Calibration curves of the product formed by the SPV reaction with oleic acid $\left(r^{2}=0.9995\right)(\mathbf{m})$ and in a mixture with lyophilized microalgae $\left(\mathrm{r}^{2}=0.9926\right)(\boldsymbol{\Lambda})$.

\section{Precision and Accuracy}

The instrumental precision was determined using 18 replicates (lyophilized and spiked with oleic acid). A RSD value found was 0.013 . The absence of proportional bias corresponds to a recovery of one, $\mathrm{R}=1$. Using lyophilized yeast cells, we found between 95.01 and $99.00 \%$ of precision and between 91.19 and $101.93 \%$ of recovery (Table 2 ).

Using lyophilized microalgae, we observed between 94.89 and $98.56 \%$ of precision and between 98.22 and $102.85 \%$ of recovery (Table 3 ). Considering the acceptance criterion (between 80 and 120\%), both intervals are considered to be suitable for this colorimetric method applied to lyophilized yeast and microalgae (Anvisa 2003).

Table 2: Average, standard deviation, repeatability and recovery achieved in the SPV method using lyophilized yeast spiked with oleic acid.

\begin{tabular}{|c|c|c|c|c|}
\hline $\begin{array}{c}\text { Oleic acid } \\
\text { (mg.mL }^{-1} \text { ) }\end{array}$ & Average & $\begin{array}{c}\text { Standard } \\
\text { deviation }\end{array}$ & Repeatability & $\begin{array}{c}\text { Recovery } \\
(\%)\end{array}$ \\
\hline 0.000 & 0.245 & 0.027 & 97.32 & \\
0.025 & 0.318 & 0.010 & 99.00 & 100.18 \\
0.05 & 0.378 & 0.020 & 98.00 & 91.19 \\
0.10 & 0.530 & 0.032 & 96.76 & 97.29 \\
0.15 & 0.692 & 0.037 & 96.27 & 101.93 \\
0.20 & 0.822 & 0.050 & 95.01 & 98.62 \\
\hline
\end{tabular}


Table 3: Average, standard deviation, repeatability and recovery achieved in the SPV method using lyophilized microalgae cells spiked with oleic acid.

\begin{tabular}{|c|c|c|c|c|}
\hline $\begin{array}{c}\text { Oleic acid } \\
\text { (mg.mL }\end{array}$ & Average & $\begin{array}{c}\text { Standard } \\
\text { deviation }\end{array}$ & Repeatability & $\begin{array}{c}\text { Recovery } \\
\text { (\%) }\end{array}$ \\
\hline 0.000 & 0.08 & 0.035 & 96.55 & - \\
0.025 & 0.225 & 0.037 & 96.33 & 99.24 \\
0.050 & 0.367 & 0.047 & 95.29 & 98.22 \\
0.100 & 0.681 & 0.051 & 94.89 & 102.85 \\
0.150 & 0.968 & 0.014 & 98.56 & 101.33 \\
0.200 & 1.238 & 0.049 & 95.08 & 99.08 \\
\hline
\end{tabular}

To date, few studies were performed to validate the SPV method using oleaginous microorganisms. Billa et al. (2014) evaluated the SPV method using Lumbriculus variegatus, a fresh water oligochaete (worm), and obtained recoveries significantly different from $1.00(\alpha=1 \%)$, indicating the presence of a proportional bias in 28 of 30 extracts.

\section{Robustness}

Robustness of the procedure was assessed by evaluating the influence of the experimental variables PV volume, reaction temperature and reaction time on the analytical performance of the method.

An analysis of Variance (ANOVA) table was constructed for the significant factors affecting the output response. The ANOVA (Table 4) indicated that the model was significant and adequate to represent the actual relationship between the response and the significant variables with a very small $p$-value $(0.05)$ and a satisfactory coefficient of determination; pvalues less than 0.05 indicate model terms are significant.

Table 4: Analysis of variance for the regression model for biomass concentration.

\begin{tabular}{|l|c|c|c|c|c|}
\hline $\begin{array}{l}\text { Source of } \\
\text { variation }\end{array}$ & $\begin{array}{c}\text { Sum } \\
\text { of } \\
\text { square }\end{array}$ & $\begin{array}{c}\text { Degrees } \\
\text { of } \\
\text { freedom }\end{array}$ & $\begin{array}{c}\text { Mean } \\
\text { square }\end{array}$ & F-value & $\boldsymbol{p}$-Value \\
\hline Regression & 0.29 & 1 & 0.29 & 14.5 & 0.0037 \\
Residual & 0.14 & 8 & 0.02 & & \\
Total & 0.44 & 9 & & & \\
\hline
\end{tabular}

$\mathrm{R}^{2}=0.8036 ;{ }^{\mathrm{a}} \mathrm{F}_{1 ; 8 ; 0,5}=5.32$

A good fit of quadratic polynomials is expressed by the coefficient of determination, $\mathrm{R}^{2}(0.8036)$. The closer the value of $\mathrm{R}^{2}$ is to 1 , the better is the correlation between the observed and predicted values. The statistical test factor, F, was used to evaluate the significance of the models and the factors at the $95 \%$ confidence level. If the calculated value of $\mathrm{F}$ is greater than the tabular $\mathrm{F}$ at the specified probability level, a statistically significant model or factor is obtained. The $\mathrm{F}_{\text {calculated }}$ value for the regression was significant and 2.73 times greater than the $F_{\text {tabulated. }}$ The small variations in any of the variables did not significantly affect the results. This provided an indication for the reliability of the proposed method during routine work.

According to the $t$ and $p$ values, only the reaction temperature $\left(x_{3}\right)$, had statistical significance. In agreement with the conclusion that the corresponding variables might be more significant if the absolute $t$ value became large and the $p$ value became smaller, the analysis indicated that the independent variables $x_{1}$ (PV volume) and $x_{2}$ (reaction time) in the investigated range did not have a significant effect on the response variable.

A Pareto plot of the standardized effects was obtained to compare the significance of each effect. As seen in the plot (Figure 5), the reaction temperature had a significant negative effect for robustness, showing that only this parameter is critical for the SPV reaction. Neither PV volume nor reaction time have statistically significant effects on the response. These results show that the reaction temperature should be fixed at the lower level $-1\left(34^{\circ} \mathrm{C}\right)$.

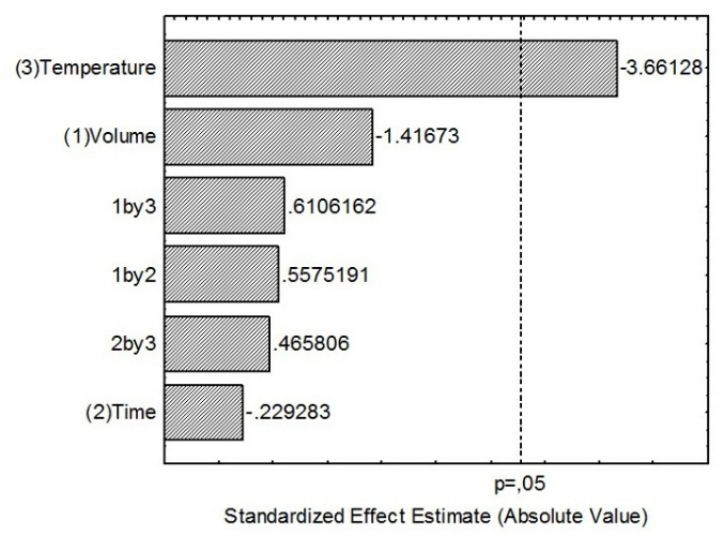

Figure 5: Pareto chart with the effect values.

\section{CONCLUSIONS}

A SPV method validation was carried out using fresh and lyophilized cells from oleaginous yeast and microalgae. All of the analytical parameters evaluated (specificity, selectivity, linearity, LD, LQ, precision, accuracy and robustness of the SPV method) during the method validation were satisfactory. The new assay method possesses many advantages com- 
pared to others described in the literature: requires only a small amount sample, less time (around $1 \mathrm{~h}$ ) and less labor and does not require organic reagents like chloroform in the reaction. Since no significant difference (according to the Tukey HSD) was found in the lipid determination when the lipid content was measured using the new method and compared to results obtained using a macro-gravimetric method and considering the validation parameters studied in this work. It was considered to be a useful analytical tool to quantify the oil in lyophilized cells (yeast and microalgae) after the fermentation process.

\section{ACKNOWLEDGEMENTS}

The authors would like to thank Anna C. Deckmann and André C. Silva for their useful comments and technical assistance. This work was supported by the following Brazilian scientific agencies: CAPES, CNPq, and São Paulo Research Foundation (FAPESP).

\section{REFERENCES}

Anschau, A., Xavier, M. C. A., Hernalsteens, S., Franco, T. T., Effect of feeding strategies on lipid production by Lipomyces starkeyi. Bioresour. Technol., 157, 214-222 (2014).

ANVISA, Guide for Validation of Analytical and Bioanalytical Methods. In: Resolution RE ${ }^{\circ} 899$ Brazil: National Agency of Sanitary Vigilance (ANVISA) (2003).

Bellou, S., Aggelis, G., Biochemical activities in Chlorella sp. and Nannochloropsis salina during lipid and sugar synthesis in a lab-scale open pond simulating reactor. J. Biotechnol., 164, 318-329 (2012).

Billa, N., Hubin-Barrows, D., Lahren, T., Burkhard, L. P., Evaluation of micro-colorimetric lipid determination method with samples prepared using sonication and accelerated solvent extraction methods. Talanta, 119, 620-622 (2014).

Bligh, E. G., Dyer, W. J., A rapid method of total lipid extraction and purification. Canadian Journal of Biochemistry and Physiology, 37, 911-917 (1959).

Chen, W., Zhang, C., Song, L., Sommerfeld, M., Hu, Q., A high throughput Nile red method for quantitative measurement of neutral lipids in micro- algae. Journal of Microbiological Methods, 77, 41-47 (2009).

Cheng, Y. S., Zheng, Y., VanderGheynst, J. S., Rapid quantitative analysis of lipids using a colorimetric method in a microplate format. Lipids, 46, 95-103 (2011).

Desvilettes, C., Bourdier, G., Amblard, C., Barth, B., Use of fatty acids for the assessment of zooplankton grazing on bacteria, protozoans and microalgae. Freshwater Biology, 38, 629-637 (1997).

Frings, C. S., Queen, C. A., Dunn, R. T., Fendley, T. W., Improved determination of total serum lipids by sulfo-phospho-vanillin reaction. Clinical Chemistry, 18, 673-674 (1972).

Haskins, S. D., Kelly, D. G., Weir, R. D., Novel pressurized solvent extraction vessels for the analysis of polychlorinated biphenyl congeners in avian whole blood. Analytica Chimica Acta, 677, 19-23 (2010).

ICH Steering Committee, International Conference on Harmonization of Technical Requirements for Registration of Pharmaceuticals for Human Use. Validation of Analytical Procedures: Methodology, November 6, Switzerland: Geneva (1996).

Inouye, L. S., Lotufo, G. R., Comparison of macrogravimetric and micro-colorimetric lipid determination methods. Talanta, 70, 584-587 (2006).

Johnson, K. R., Ellis, G., Toothill, C., Sulfophosphovanillin reaction for serum lipids reappraisal. Clinical Chemistry, 23, 1669-1678 (1977).

Knight, J. A., Rawle, J. M., Anderson, S., Chemical basis of sulfo-phospho-vanillin reaction for estimating total serum lipids. Clinical Chemistry, 18, 199-202 (1972).

Landrum, P. F., Gedeon, M. L., Burton, G. A., Greenberg, M. S., Rowland, C. D., Biological responses of Lumbriculus variegatus exposed to fluoranthene spiked sediment. Archives of Environmental Contamination and Toxicology, 42, 292-302 (2002).

Lu, Y., Ludsin, S. A., Fanslow, D. L., Pothoven, S. A., Comparison of three microquantity techniques for measuring total lipids in fish. Canadian Journal of Fisheries and Aquatic Sciences, 65, 22332241 (2008).

Makri, A., Bellou, S., Birkou, M., Papatrehas, K., Dolapsakis, N. P., Bokas, D., Papanikolaou, S., Aggelis, G., Lipid synthesized by micro-algae grown in laboratory- and industrial-scale bioreactors. Engineering in Life Sciences, 11, 52-58 (2011). 
Nakamatsu, Y., Tanaka, T., Food resource use of hyperparasitoid Trichomalopsis apanteloctena (Hymenoptera: Pteromalidae), an idiobiotic ectoparasitoid. Annals of the Entomological Society of America, 97, 994-999 (2004).

Ratledge, C., Regulation of lipid accumulation in oleaginous micro-organisms. Biochemical Society Transactions, 30, 1047-1050 (2002).

Ribani, M., Bottoli, C. B. G., Collins, C. H., Jardim, I. C. S. F., Melo, L. F. C., Validation for chromatographic and electrophoretic methods. Quimica
Nova, 27, 771-780 (2004).

Turlo, J., Gutkowska, B., Herold, F., Effect of selenium enrichment on antioxidant activities and chemical composition of Lentinula edodes (Berk.) Pegl. mycelial extracts. Food and Chemical Toxicology, 48, 1085-1091 (2010).

Visavadiya, N. P., Narasimhacharya, A. V. R. L., Asparagus root regulates cholesterol metabolism and improves antioxidant status in hypercholesteremic rats. Evidence-Based Complementary and Alternative Medicine, 6, 219-226 (2009). 